\title{
COMPENSADOR SÉRIE DE TENSÃO EM ONDA QUADRADA PARA MITIGAÇÃO DE AFUNDAMENTOS DE TENSÃO
}

\author{
Igor Amariz Pires* \\ iap@ufmg.br
}

\author{
Braz de Jesus Cardoso Filho* \\ cardosob@ufmg.br
}

\author{
Sidelmo Magalhães Silva* \\ sidelmo@ufmg.br \\ *Laboratório de Aplicações Industriais \\ Universidade Federal de Minas Gerais \\ Av. Antônio Carlos, 6627 - Pampulha - CEP 31270-901 \\ Belo Horizonte - MG - Brasil - +55-31-3409-4840
}

\section{ABSTRACT}

Series Voltage Compensators (SVC) are used to mitigate power quality problems related to voltage distortion issues. The most known SVC are the DVR ${ }^{\mathrm{TM}}$ (Dynamic Voltage Restorer) and $\mathrm{DySC}^{\mathrm{TM}}$ (Dynamic Sag Corrector), which are used to protect sensitive loads. The voltage injected by the DVR is sinusoidal, produced by an H-bridge inverter which is modulated using Pulse Width Modulation (PWM) and a sinusoidal output filter. Considering that voltage sags are fast phenomena that usually last hundreds of milliseconds, this paper proposes the use of square-wave voltages to compensate sags as well as the control strategy for the compensator. Experimental results show the effectiveness of the injection of a square-wave voltage for the protection of electronic loads.

KEYWORDS: Sag, Series Voltage Compensator, Power Quality.

\section{RESUMO}

Compensadores Série de Tensão (CST) são utilizados para mitigação de fenômenos de qualidade da energia elétrica re-

Artigo submetido em 31/12/2010 (Id.: 1239)

Revisado em 10/03/2011, 17/05/2011, 19/07/2011

Aceito sob recomendação do Editor Associado Prof. Francisco de Assis dos Santos Neves lacionados a distúrbios na tensão. Os mais conhecidos entre os CSTs são o DVR ${ }^{\mathrm{TM}}$ (Dynamic Voltage Restorer) e o DySC $^{\mathrm{TM}}$ (Dynamic Sag Corrector), utilizados para proteção de cargas elétricas sensíveis a afundamentos de tensão. A tensão injetada pelo restaurador é senoidal, sintetizada através de um inversor em ponte-H modulado em alta frequência por PWM (Pulse Width Modulation), em conjunto com um filtro de saída senoidal. Considerando a duração típica dos afundamentos da ordem de centenas de milisegundos, este artigo propõe a implementação de um CST com injeção de tensão em onda quadrada, sendo incluídos, ainda, aspectos relativos à estratégia de controle para injeção de tensão. Resultados experimentais mostram a eficácia da injeção em onda quadrada na proteção de cargas eletrônicas.

PALAVRAS-CHAVE: Boost, boost intercalado, dual boost, filtro de EMI, PFC, ruído DM e CM.

\section{INTRODUÇÃO}

Compensadores Série de Tensão (CST) são dispositivos que auxiliam na mitigação de vários fenômenos de qualidade de energia (Bollen, 1999), dentre eles:

- afundamentos de tensão;

- sobretensões;

- desequilíbrio de tensão; 
- harmônicos de tensão;

- flicker;

- transitórios de chaveamento.

Dentre os problemas de qualidade de energia, o mais importante a ser mitigado pelo CST é o afundamento de tensão. Afundamentos de tensão são fenômenos de curta duração (0,5 ciclo a 1 minuto) nos quais a tensão sofre uma redução na sua amplitude para valores entre 0,1 e 0,9 pu (IEEE Std 1159, 1995). Este distúrbio de tensão será o foco deste artigo.

O Compensador Série de Tensão é tipicamente um equipamento instalado entre a rede elétrica e a carga a ser protegida. Na ocorrência de um distúrbio, como um afundamento de tensão, o CST injeta uma tensão em série ao sistema para compensar a pertubação existente. A fig. 1 mostra um exemplo para um afundamento de tensão: o CST injeta a tensão necessária para que a carga seja fornecida com tensão em valores nominais.

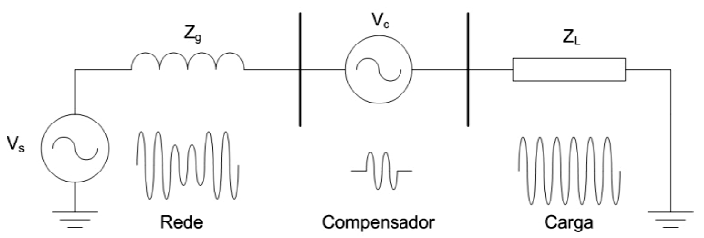

Figura 1: Princípio de operação do Compensador Série de Tensão.

Na implementação de um CST, quatro topologias básicas são utilizadas (Nielsen and Blaabjerg, 2005), conforme ilustrado na fig. 2. Todas as topologias possuem um conversor série. Este é invariavelmente constituído por um inversor com modulação PWM de alta frequência, em conjunto com um filtro senoidal, conforme ilustrado na fig. 3. Este filtro é usualmente um filtro LC de $2^{a}$ ordem, sendo que a indutância deste filtro inclui a indutância de dispersão do transformador série.

Nas topologias Fig.2.a e Fig.2.b, encontram-se o conversor shunt, o transformador série e o conversor série que alimentam o barramento de corrente contínua (c.c.). A função destes componentes é fornecer a potência ativa para compensação dos distúrbios. Por se tratarem de elementos passivos, dispensam qualquer tipo de controle. Para as topologias Fig. 2.c e Fig 2.d, há armazenagem da energia que é utilizada no instante da compensação. Estas topologias necessitam de um controle bi-direcional no conversor série: este é responsável por injetar a tensão (e potência) no instante do afundamento e também retirar a energia da rede, quando não há distúrbios, para carregar os elementos de armazenagem de energia.

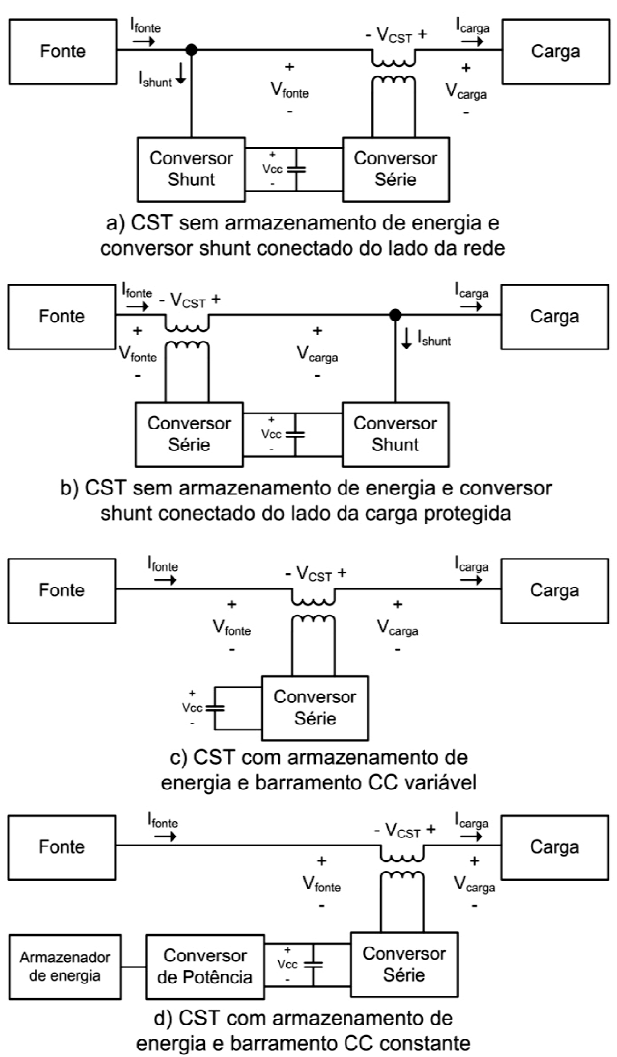

Figura 2: Topologias CST.

O primeiro Compensador Série de Tensão comercialmente utilizado para mitigação de afundamentos de tensão foi o DVR $^{\mathrm{TM}}$ (Dynamic Voltage Restorer), em português Restaurador Dinâmico de Tensão (Woodley et al., 1999). Tratava-se de um equipamento com 2 MVA de potência e projetado para redes de $12,47 \mathrm{kV}$. Como topologia, utilizava-se um CST com armazenagem de energia e barramento c.c. constante (topologia fig. 2.d). A medida que outros CSTs comerciais foram surgindo, como o DySC ${ }^{\mathrm{TM}}$ - Dynamic Sag Corrector (Brumsickle et al., 2001; Pryde, 2008), percebe-se uma tendência à utilização das topologias sem armazenamento de energia, por duas principais vantagens: menor custo de manutenção (dispensa substituição periódica de elementos armazenadores de energia, tais como bateria) e possibilidade de compensação de fenômenos de maior duração. Nesta mesma topologia, para baixas tensões, o transformador série foi retirado, reduzindo volume e custo do CST (Brumsickle et al., 2001; Silva et al., 2005).

Vários trabalhos acerca de CSTs no cenário nacional foram realizados. Em Costa Jr. et al. (2004) propõe-se um controle para o CST senoidal. Neste trabalho, a topologia a ser controlada é da Fig 2.a. Também em Marafão et al. (2008) é 


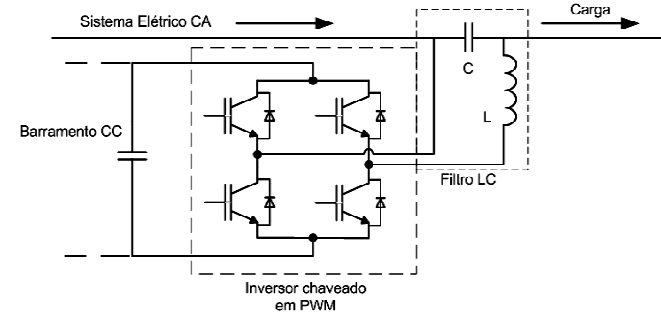

Figura 3: Estágio de saída de um compensador série de tensão com inversor PWM e filtro senoidal LC.

proposto um controle para a tensão de saída do CST senoidal, topologia Fig 2.a. Na referência Bianchin et al. (2008) é apresentado uma metodologia para a escolha de CST senoidal para utilização em linhas de distruibuição. Em Soeiro et al. (2009) topologias de condicionadores de energia, utilizando conversão c.a.-c.a. direta, sem barramento c.c., são discutidos para aplicação na mitigação de afundamentos de tensão.

Como os afundamentos de tensão são eventos de curta duração, a tensão injetada pelo compensador não precisa ser necessariamente senoidal, uma vez que não há qualquer impacto significativo do ponto de vista de conteúdo harmônico, em termos do tempo total de medição da distorção harmônica de tensão. Esta medição, conforme PRODIST (2008), é realizada em intervalos consecutivos de 10 minutos de duração. Em geral, cargas elétricas operam normalmente com tensões distorcidas por curtos intervalos de tempo. Exemplos de cargas pouco sensíveis à distorção harmônica da tensão são as cargas eletrônicas (fontes de alimentação), como os Controladores Lógicos Programaveis (CLPs) e os microcomputadores (PCs). Algumas UPS (Uninterruptible Power Supply) utilizam tensão em onda quadrada para alimentar suas cargas durante desligamentos da rede de energia elétrica.

Este artigo propõe a utilização de injeção de tensão em onda quadrada pelo CST no instante de ocorrência do afundamento de tensão. Este trabalho investiga a utilização em onda quadrada para mitigação apenas de afundamentos de tensão, visto ser este problema um dos mais recorrentes na área de qualidade da energia elétrica. Como principal vantagem nesta escolha está a simplificação do CST através da eliminação do filtro senoidal de saída e diminuição nas perdas por chaveamento do conversor série. Na próxima seção, a compensação por tensão em onda quadrada é apresentada, sendo também demostranda a sua eficácia na proteção de cargas eletrônicas. A utilização da onda quadrada simplifica também o seu controle. Resultados experimentais de um CST injetando tensão em onda quadrada e protegendo cargas eletrônicas são mostrados ao final deste artigo. Uma compa- ração entre o CST senoidal e em Onda Quadrada em termos de custo também é apresentada.

\section{COMPENSADORES SÉRIE DE TENSÃO EM ONDA QUADRADA}

Cargas eletrônicas tem em seu estágio de entrada um retificador formado por uma ponte de diodos, um filtro capacitivo (retificador diodo-capacitor) e um regulador de tensão, conforme ilustrado na fig. 4. Sempre que a tensão de entrada é maior que a tensão no capacitor, a ponte de diodos entra em condução, carregando o capacitor. Quando há ocorrência de um afundamento de tensão, a tensão c.a. remanescente é inicialmente inferior à tensão no capacitor, impedindo que o retificador entre em condução e que este mesmo capacitor seja carregado. O capacitor então descarrega-se por ação da carga e a tensão não-regulada no barramento c.c. irá diminuir até alcançar o pico da tensão remanescente, conforme ilustrado na fig. 5(a). Esta figura mostra o comportamento da tensão do barramento c.c. para um afundamento de 0,6 pu. Como para o regulador o que importa é o nível da sua tensão c.c. de entrada, a manutenção da amplitude de pico da onda de tensão c.a. de entrada do retificador é suficiente para a proteção de cargas eletrônicas contra os afundamentos de tensão. A fig. 5(b) ilustra a proposta deste trabalho: para um afundamento de tensão com tensão residual igual a $0,6 \mathrm{pu}$ injetou-se uma tensão em onda quadrada de $0,4 \mathrm{pu}$. $\mathrm{O}$ barramento c.c. de um retificador com filtro capacitivo (fig. 4) se manteve constante durante o afundamento de tensão (fig. 5(b)). Logo, o CST pode trabalhar com injeção de tensão em onda quadrada com o objetivo de regular o valor de pico da tensão c.a. na entrada do retificador (Pires and de Jesus Cardoso Filho, 2009).

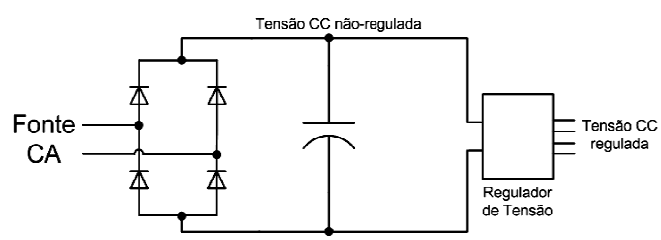

Figura 4: Estágio inicial em fontes c.a.-c.c. de equipamentos eletrônicos.

Afundamentos de tensão começaram a se tornar um problema crônico no ambiente industrial a partir da automatização dos processos produtivos, com a inserção de inúmeros elementos eletrônicos (McGranaghan et al., 1993). O CST em onda quadrada proposto tem um foco voltado para este tipo de carga. A princípio o CST em onda quadrada pode possuir qualquer nível de potência. A forma otimizada de mitigação de afundamentos de tensão é o uso de compensadores de baixa potência protegendo cargas eletrônicas nos 


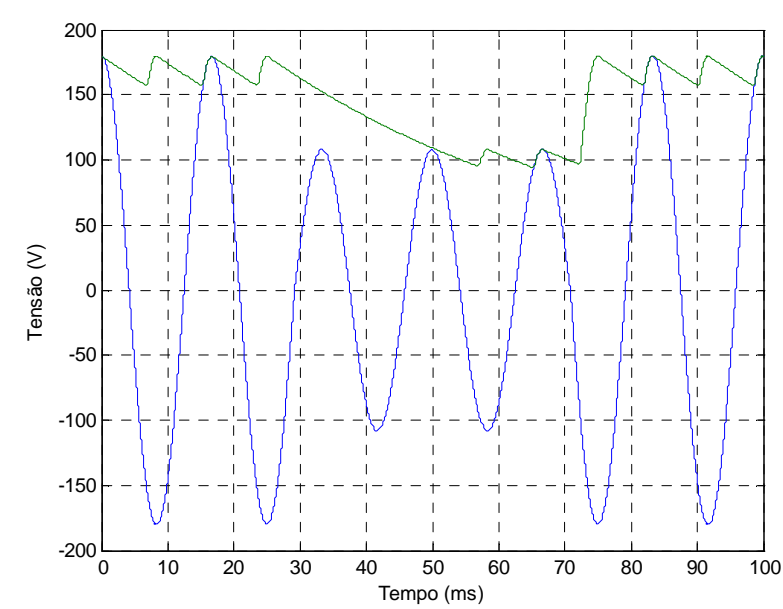

(a) Barramento c.c. submetido a um afundamento de tensão de 0,6 pu.

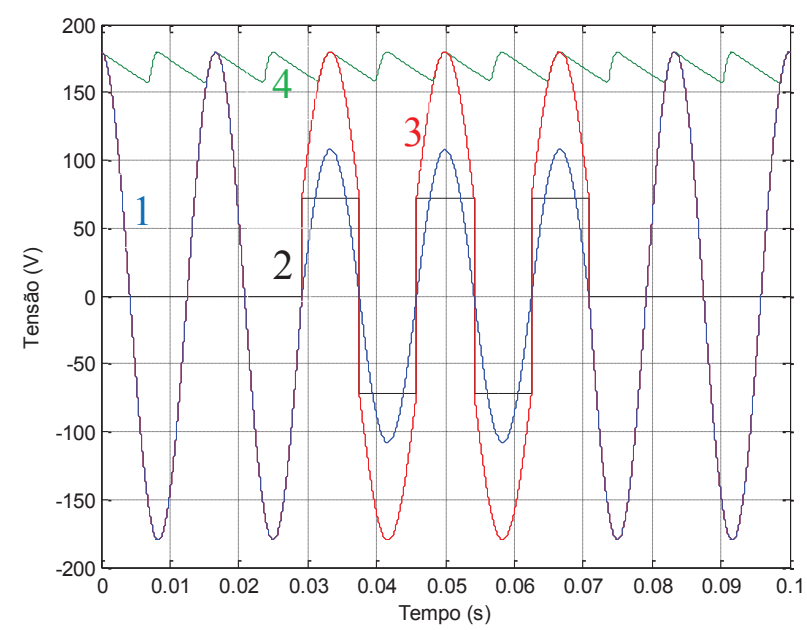

(b) Mitigação de afundamento de tensão de 0,6 pu através da injeção de tensão em onda quadrada. Azul (1) : Tensão de entrada; Preto (2): Tensão em onda quadrada injetada pelo compensador; Vermelho (3): Tensão de Compensação $=$ tensão de entrada + tensão em onda quadrada; Verde (4): Barramento c.c. da fonte c.a.-c.c. protegida.

Figura 5: Exemplo de mitigação de Afundamento de Tensão utilizando Onda Quadrada para Equipamentos Eletrônicos

processos mais críticos de uma indústria, reduzindo assim o investimento inicial.

Na fig. 6 mostra-se o circuito de potência básico de um compensador série em onda quadrada. O circuito básico é formado pelos seguintes elementos:

\section{Transformador shunt}

2. Retificador em onda completa
3. Barramento C.C.

4. Inversor em ponte $\mathrm{H}$

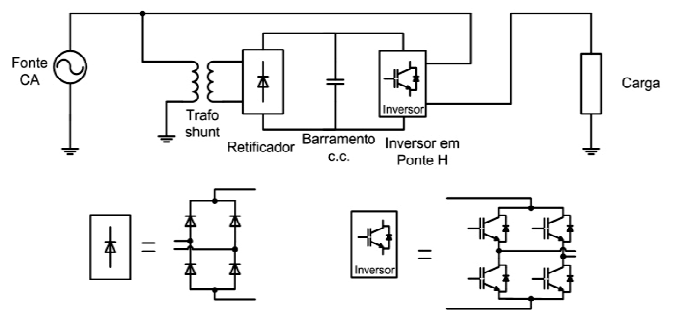

Figura 6: Célula básica do compensador série de tensão em onda quadrada.

A vantagem da compensação em onda quadrada sobre a compensação senoidal está na simplificação do CST. A operação do inversor em onda quadrada na frequência da rede c.a. implica nos seguintes pontos positivos: (1) redução do calor gerado nas chaves estáticas de saída; (2) aumento da eficiência do conversor; (3) eliminação do modulador PWM; (4) eliminação do filtro LC de saída. O principal ponto negativo desta proposta é a tensão de compensação fixa, resultado da eliminação da modulação de largura de pulso. Esta restrição potencialmente limita o interesse na compensação em onda quadrada e deve ser atacada.

A variação da amplitude da tensão de compensação em onda quadrada pode ser obtida através da topologia multinível em cascata, conforme visualizado na fig. 7. Nesta proposta, temse o equivalente a uma modulação em amplitude da tensão de compensação. O compensador é constituído por um grupo de $n$ células, como as ilustradas na fig. 6, conectadas em cascata. A proposta de uma topologia multinível em cascata já foi anteriormente utilizada, sendo encontrada em Loh et al. (2004). O objetivo do trabalho era sintetizar um onda de média tensão com chaves semicondutores de baixa tensão e sem o transformador série. Vale destacar também que a modulação utilizada era PWM e não em onda quadrada. O uso desta estrutura multinível em cascata para uso em médias tensões pode também ser encontrado em Hill and Harbourt (1999). Trata-se do uso da topologia multinível para acionamento de motores de indução de média tensão, sendo que o uso da ponte-H em cascata para este objetivo foi patenteada pela empresa Robicon.

A relação de transformação de cada transformador shunt pode ser igual ou diferente de uma célula para outra. Os modos de operação do CST Multinível com duas células são apresentados na fig. 8. Nesta figura, a estrutura multinível conta com duas células. Considerando que o nível $_{2}$ é maior que o nivel 1 , o CST com duas células pode ser modulada 


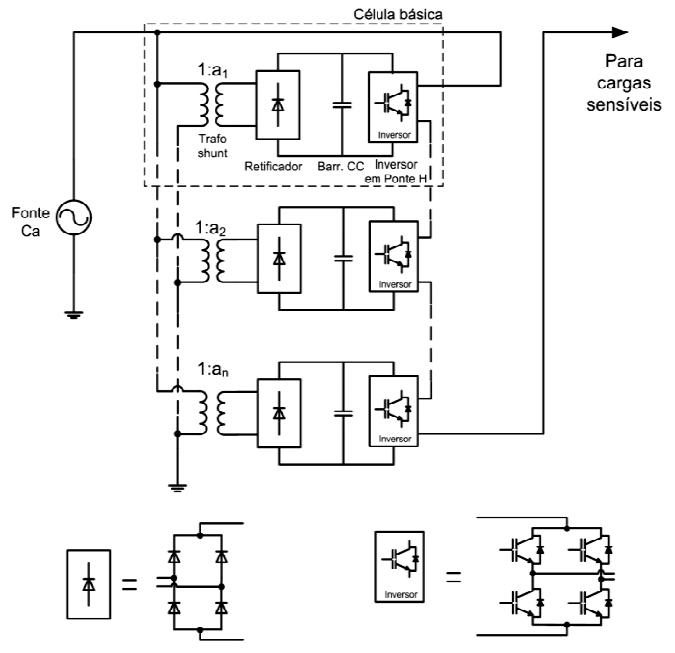

Figura 7: Topologia monofásica do compensador série de tensão multinível.

em nove níveis de tensão: $+\left(\right.$ nivel $_{1}+$ nivel $\left._{2}\right),+$ nivel ${ }_{2}$, $+\left(\right.$ nivel $_{2}-$ nivel $\left._{1}\right),+$ nivel $_{1}, 0,-$ nivel $_{1},-$ nivel $_{2}-$ nivel $\left._{1}\right),-$ nivel $_{2},-\left(\right.$ nivel $_{1}+$ nivel 2$)$. O compensador funciona em hot stand-by: na ausência de problemas de distúrbios de energia, injeta-se uma tensão de $0 \mathrm{~V}$. Na ocorrência de afundamento, injeta-se o nível necessário para a recuperação da tensão de adequada ao bom funcionamento do equipamento protegido. A fig. 9 mostra os níveis de tensão disponíveis através dos modos de operação apresentados na fig. 8 .

O número de células do compensador passa a ser uma preocupação, pois uma grande quantidade destas inviabilizaria esta solução. Para otimização do número de células, recorrese a normas internacionais que recomendam que equipamentos eletrônicos devam funcionar com tensões de alimentação variando entre 0,9 e 1,05 pu (ANSI-C84.1, 2006; IEEE Std 1159, 1995). Assim, uma onda quadrada de amplitude fixa pode ser utilizada para a compensação de uma faixa relativamente larga de afundamentos. Para a escolha da relação de transformação do transformador shunt e também determinação da faixa de afundamento de tensão que esta relação de transformação irá compensar, utiliza-se a teoria de matemática intervalar (Kolev, 1993). Considerando $V_{1}$ e $V_{2}$ as tensões que representam os afundamentos, $V_{1}<V_{2}$ e $1: a$ a relação de transformação do transformador shunt da célula básica, as eq. (1) a (4) fornecem os valores a serem considerados para recuperação do afundamento de tensão, conforme normas internacionais (ANSI-C84.1, 2006; IEEE Std 1159, 1995). O objetivo é utilizar uma célula para compensar uma faixa de afundamentos, recuperando a tensão para valores entre 0,9 e $1,05 \mathrm{pu}$.
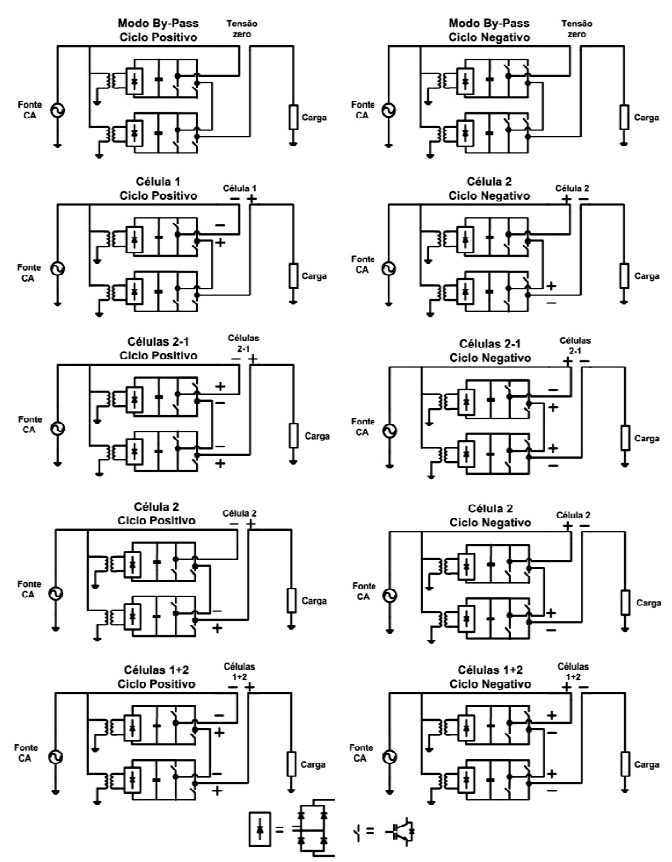

Figura 8: Modos de operação do compensador série de tensão.

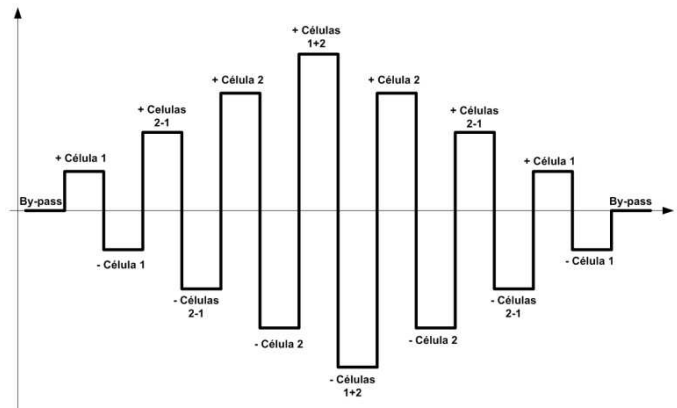

Figura 9: Valores de tensões disponíveis pelos modos de operação do Compensador Série de Tensão.

$$
\begin{gathered}
{\left[V_{1}: V_{2}\right]+a\left[V_{1}: V_{2}\right]=[0,9: 1,05]} \\
(1+a)\left[V_{1}: V_{2}\right]=[0,9: 1,05] \\
V_{1}=\frac{0,9}{1+a} \\
V_{2}=\frac{1,05}{1+a}
\end{gathered}
$$


Como exemplo do uso das eq. (3) e (4), para uma relação de transformação $1: a=1: 0,2 p u, V_{1}=0,75 p u$ e $V_{2}=0,875 \mathrm{pu}$. Isto quer dizer que, se na célula da fig. 6 o transformador shunt tivesse uma relação $1: 0,2$, a faixa de afundamentos compensados, recuperando o pico da tensão para valores entre 0,9 e $1,05 \mathrm{pu}$, seria entre 0,75 e 0,875 pu.

A fig. 10 auxilia na compreensão da correlação entre a relação de transformação de um célula de injeção em onda quadrada necessária e a faixa de afundamentos de tensão visando a recuperação entre 0,9 e 1,05 pu de tensão. Como exemplo, a fig. 10 traz uma compensação por CST com duas células: uma com uma relação de transformaçao de 1:0,2 pu e outra com 1:0,6 pu. Com 1:0,2, pode-se compensar afundamentos entre $0,75 \mathrm{pu}(0,75+0,75 \times 0,2=0,9) \mathrm{e}$ 0,875 pu $(0,875+0,875 \times 0,2=1,05)$. Para um nível de compensação de 0,4 pu (nível 1:0.06-1:0,02), pode-se compensar afundamentos de $0,64 \mathrm{pu}(0,64+0,64 \times 0,4=0,90 \mathrm{pu})$ a $0,75 \mathrm{pu}(0,75+0,75 \times 0,4=1,05)$. Com 1:0.06, os afundamentos compensados são de $0,56 \mathrm{pu}(0,56+0,56 \times 0,6=$ $0,9)$ a $0,65 \mathrm{pu}(0,65+0,65 \times 0,6=1,05)$. Com as duas células injetando ao mesmo tempo, a relação de transformação passa a ser de 1:0,8. Neste caso, a compensação se dá para afundamentos de $0,50 \mathrm{pu}(0,50+0,50 \times 0,8=0,9)$ a $0,58 \mathrm{pu}$ $(0,58+0,58 \times 0,8=1,05)$. Um compensador com duas células, uma com relação de transformação de 1:0,2 e outra para 1:0,6, compensa, portanto, afundamentos entre 0,50 e 0,87 pu.

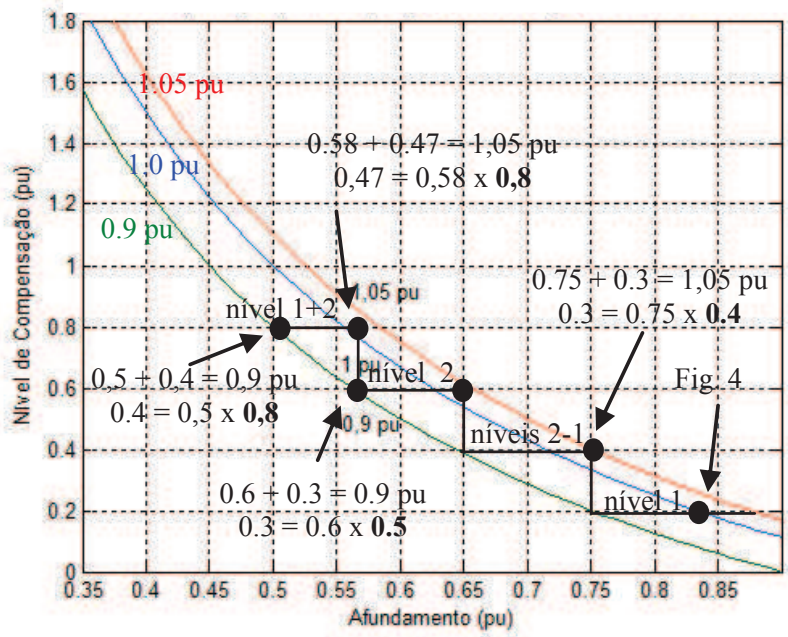

Figura 10: Nível de compensação para recuperação do valor de pico da tensão de entrada.

Estudo da Melhorn et al. (2005) em 12 concessionárias de energia norte-americanas e uma chinesa mostrou que $80 \%$ dos afundamentos têm uma tensão residual maior que $50 \%$. Assim, com o exemplo citado, utilizando células 1:0,2 e
1:0,6, haveria mitigação de $80 \%$ dos afundamentos mais frequentes.

A fim de avaliar o número necessário de células para mitigar toda a faixa de afundamentos, a tabela 1 traz a relação entre os afundamentos compensados e o número de células utilizadas. Além das células 1:0,2 e 1:0,6, cada nova célula incluída tem uma relação de 1:1. Esta escolha é realizada para se ter a mesma tecnologia de componentes semicondutores (baixa tensão) em cada célula. Para fins de simplificação, cada célula, independente da sua relação de transformação, terá um custo de 1 pu. A fig. 11 traz a correlação entre o número de células e a porcentagem de afundamentos compensados, bem como o crescimento de custo a inserção de cada nova célula.

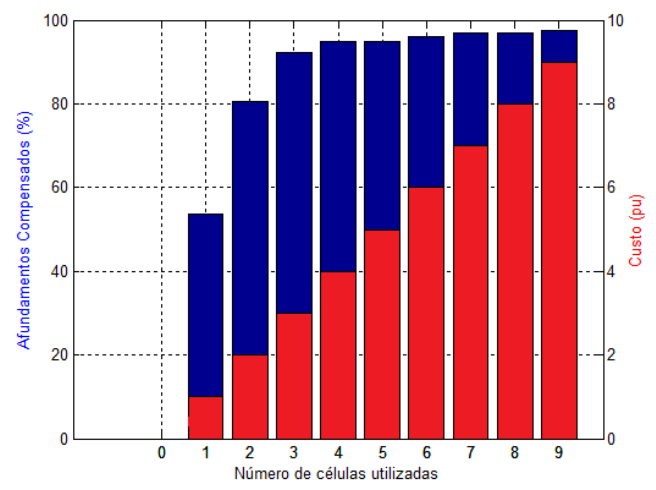

Figura 11: Custo e porcentagem de afundamentos compensados conforme número de células utilizadas para o CST multinível em Onda Quadrada.

Analisando a tabela 1 e a fig. 11, percebe-se que acima de 3 células, há pequenos ganhos na porcentagem de afundamentos compensados. Um compensador com um número de células acima de 3 não teria uma boa relação custo-benefício. Entretanto, o número ideal, em termos de porcentagem de afundamentos compensados e custo, é do CST contendo duas células. Conforme analisado anteriormente, $80 \%$ dos afundamentos mais frequentes são recuperados. O compensador miniDySC, comercializado pela empresa Soft Switch Technology, compensa afundamentos de até $50 \%$. Este dado dá uma idéia da necessidade de mercado, sendo uma informação importante para o projeto de Compensadores Série de Tensão.

\section{CONTROLE DO COMPENSADOR SÉ- RIE DE TENSÃO EM ONDA QUADRADA}

A compensação por onda quadrada faz com que o chaveamento dos elementos inversores de saída ocorram na frequência da rede elétrica. A eliminação da modulação PWM elimina por sua vez a necessidade de utilização de microprocessadores rápidos. Na realidade, a injeção de onda quadrada 
Tabela 1: Número de células vesus porcentagem de afundamentos compensados (Melhorn et al., 2005).

\begin{tabular}{|l|l|l|l|l|}
\hline Número de células & $\begin{array}{l}\text { Relações de } \\
\text { transformação }\end{array}$ & $\begin{array}{l}\text { Faixa de Afunda- } \\
\text { mento Compensada } \\
\text { (pu) }\end{array}$ & $\begin{array}{l}\text { Porcentagem de } \\
\text { afundamentos } \\
\text { compensados }\end{array}$ & $\begin{array}{l}\text { Ganho na Porcenta- } \\
\text { gem }\end{array}$ \\
\hline 1 & $1: 0,02$ & 0,75 a 0,9 & 41,9 & 41,9 \\
\hline 2 & $1: 0,02+1: 0,06$ & 0,50 a 0,9 & 80,5 & 38,6 \\
\hline 3 & $1: 0,02+1: 0,06+1 \times 1: 1$ & 0,32 a 0,9 & 90,4 & 9,9 \\
\hline 4 & $1: 0,02+1: 0,06+2 \times 1: 1$ & 0,24 a 0,9 & 93,5 & 3,1 \\
\hline 5 & $1: 0,02+1: 0,06+3 \times 1: 1$ & 0,19 a 0,9 & 95,9 & 2,3 \\
\hline 6 & $1: 0,02+1: 0,06+4 \times 1: 1$ & 0,16 a 0,9 & 95,5 & 0,0 \\
\hline 7 & $1: 0,02+1: 0,06+5 \times 1: 1$ & 0,13 a 0,9 & 96,9 & 1,0 \\
\hline 8 & $1: 0,02+1: 0,06+6 \times 1: 1$ & 0,12 a 0,9 & 96,9 & 0,0 \\
\hline 9 & $1: 0,02+1: 0,06+7 \times 1: 1$ & 0,10 a 0,9 & 97,6 & 0,7 \\
\hline
\end{tabular}

possibilita o controle do CST para mitigação de afundamentos de tensão com uma lógica bastante simples, que pode ser implementada através de poucos elementos discretos.

A filosofia do controle do CST em onda quadrada encontrase representada em diagramas de blocos por meio da fig. 12. Trata-se de um controle em malha aberta (feedforward) onde deseja-se rejeitar a perturbação correspondente à variação da amplitude da tensão c.a. da rede de energia. O primeiro estágio se baseia no comportamento da tensão c.c. não-regulada das fontes de alimentação dos equipamentos eletrônicos descritos genericamente na fig. 4. Neste estágio é realizada uma estimativa da tensão c.c. não-regulada da carga eletrônica a ser protegida na ocorrência do afundamento de tensão. Esta tensão estimada segue para um circuito que seleciona qual ou quais níveis de tensão devem ser injetados. Em paralelo há um circuito que informa a polaridade da tensão c.a. de entrada. Com estes dois sinais, a informação de nível e sinal da tensão da rede, define-se o estado do inversor de saída em cada célula.

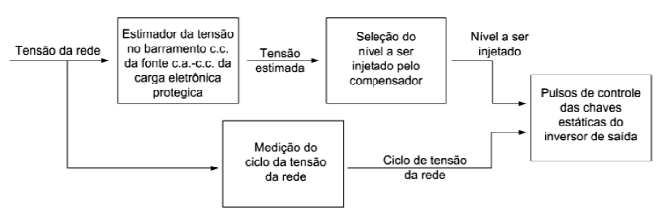

Figura 12: Filosofia do controle do CST em onda quadrada.

Como dito anteriormente, uma possível implementação desta estratégia de controle através de componentes discretos é ilustrada na fig. 13. Três elementos se destacam nesta topologia: estimador diodo-capacitor-resistor (DCR), comparadores de nível e detector de sinal. O estimador DCR fornece a amplitude do afundamento de tensão. O estimador DCR detecta o valor de pico da tensão de entrada. Na ocorrência do afundamento, a tensão de entrada se torna menor que a tensão no capacitor $C$, fazendo com que a ponte de diodos não conduza. $\mathrm{O}$ capacitor descarrega pelo resistor $R$ até que seu valor de tensão se torne igual ao valor de pico da tensão de entrada. A tensão do barramento c.c. após este transitório de descarga é, portanto, uma medida do afundamento presente. Os comparadores de nível realizam uma comparação entre a saída do estimador $D C R$ e valores de referência para injeção de tensão correspondente a cada uma das duas células do compensador. Estes valores de referência são escolhidos a partir da fig. 10 e equações 3 e 4 .

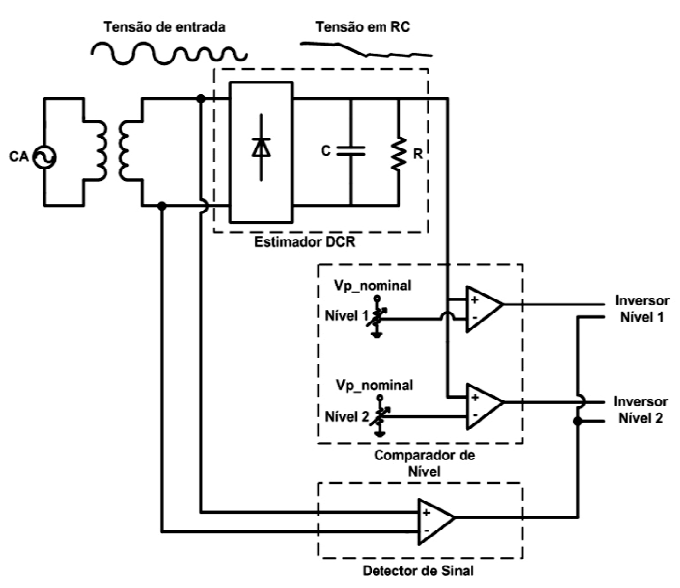

Figura 13: Controle por componentes discretos.

$\mathrm{O}$ detector de sinal (fig. 13) informa aos elementos de acionamento dos inversores na saída se a tensão de entrada é positiva ou negativa. Com distorção típica de tensão (5\%), esta informação ainda é válida, pois, na proteção de cargas eletrônicas, o objetivo é garantir a tensão de pico entre 0,9 e 1,05 pu nos instantes de carga do capacitor do barramento c.c. . Este instante se dá por volta da metade do semi-ciclo da tensão de entrada. Se houver alguma oscilação na transição entre um semi-ciclo e outro, a compensação para a carga ele- 
trônica não ficará comprometida, pois o instante de condução de corrente será no meio do semi-ciclo, momento que não ocorre variações de sinal na tensão de entrada. São necessários os sinais de controle vindos do comparador de nível e detector de sinal para o controle do inversor de cada célula, porque o inversor contêm três possíveis estados $(+\mathrm{Vd}$, $0,-\mathrm{Vd})$.

O tempo de resposta deste controle é dado em função da faixa de passagem do estimador DCR. Por se tratar de um circuito $\mathrm{RC}$, admitindo que a tensão de pico na entrada da ponte de diodos seja $V_{o}$ e $V_{p}$ a tensão de pico no capacitor, tensão inicial no processo de descarga do mesmo, o tempo de resposta a um afundamento é dado por:

$$
t=-R C \ln \left(\frac{V_{o}}{V_{p}}\right)
$$

Este tempo de resposta deve ser menor que um ciclo da tensão da rede, tempo mínimo de funcionamento sem compensação da tensão de entrada para equipamentos eletrônicos, segundo normas internacionais (ANSI-C84.1, 2006; IEEE Std 1159, 1995). A fig. 14 apresenta este tempo de resposta para um resistor de $2,7 k \Omega$ e capacitor de $4,7 \mu F$. Analisando a figura, o tempo de resposta aumenta com a redução da tensão residual do valor de afundamento. Para um afundamento específico bastaria diminuir o resistor ou capacitor para diminuição deste tempo, conforme equação 5. Entretanto, a diminuição no valor destes componentes traz uma elevação no ripple do estimador DCR. Um ripple elevado pode fazer com que um nível não adequado à compensação seja injetado por alguns instantes. Uma alternativa para reduzir-se o tempo necessário para a compensação de afundamentos mais profundos é a utilização de uma fonte de corrente para a descarga do capacitor do estimador em substituição ao resistor $R$.

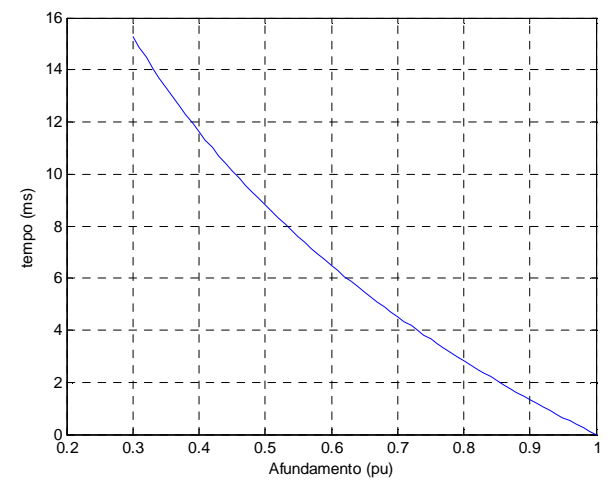

Figura 14: Tempo de resposta para um estimador DCR com $C=4,7 \mu F$ e $R=2,7 k \Omega$.
O circuito proposto na fig. 12 faz com que o compensador injete tensão sempre em fase com o distúrbio da rede. Havendo um salto de fase, a injeção acompanha este salto. Para cargas eletrônicas, esta defasagem com a tensão recuperada não gera qualquer inconveniente. $\mathrm{O}$ foco deve ser a manutenção da tensão no barramento c.c. na entrada dos reguladores, possibilitando o seu funcionamento contínuo.

\section{APLICAÇÃO DO CST EM ONDA QUA- DRADA NAS REDES TRIFÁSICAS}

Para o caso de redes trifásicas, a estrutura apresentada na fig. 7 deve ser replicada para cada fase, conforme identificado na fig. 15. Com esta topologia por fase, é possível compensar afundamentos desequilibrados. Entretanto, especial atenção deve ser dada ao controle do compensador. Conforme seção anterior, a proposta de controle deve também ser replicada para cada fase. O problema nesta ação está no fato de que a onda quadrada injetada permanece em fase com a tensão em afundamento. Havendo um salto de fase, a onda de tensão proveniente do compensador também terá este salto de fase. Enfim, a recuperação será parcial, apenas de amplitude e não completa, o que incluiria amplitude e fase.

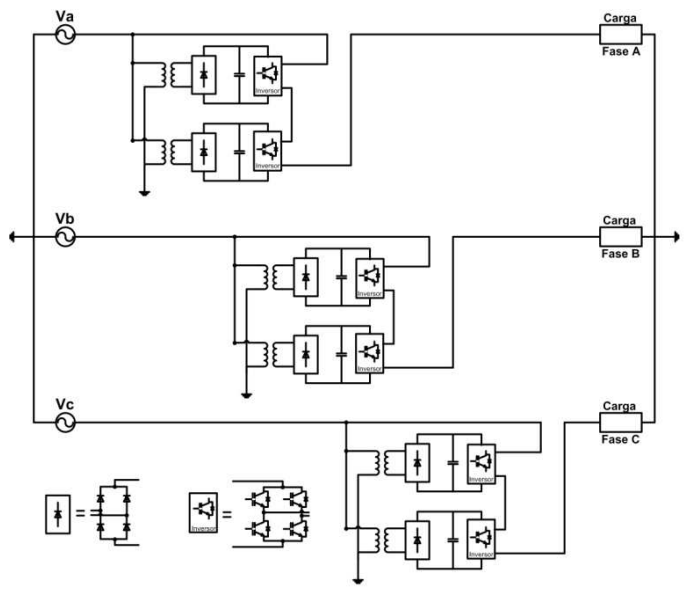

Figura 15: CST em onda quadrada trifásico.

Para total mitigação do afundamento, em termos de amplitude e fase, é necessário a injeção de uma tensão fora de fase visando a recuperação da tensão de entrada. A fig 16 ilustra uma alternativa de controle para sistemas trifásicos. Neste caso, utiliza-se um PLL (Phase-Locked Loop) trifásico que rastreia a fase e amplitude das tensões da rede c.a., na forma vetorial, existentes antes do afundamento e são tomadas como referência. Com estas tensões de referências, é realizada uma subtração destas com as tensões de entrada. A tensão de erro resultante é exatamente a tensão a ser injetada. 


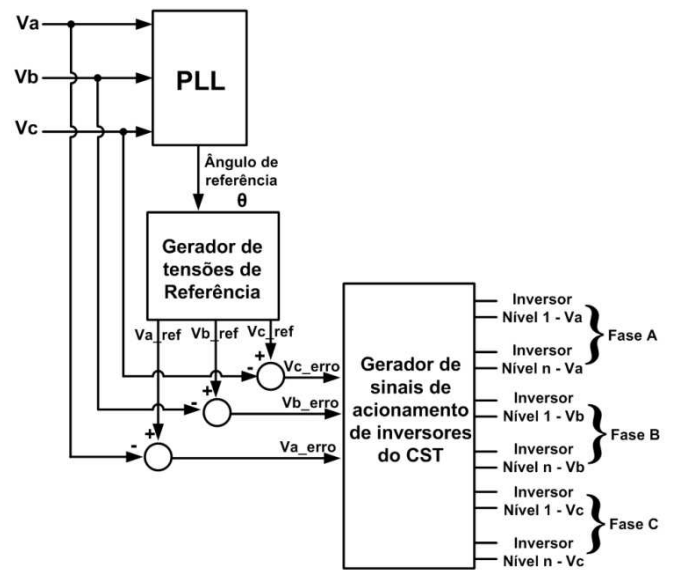

Figura 16: Controle para CST em onda quadrada trifásico.

\section{RESULTADOS EXPERIMENTAIS}

Para o teste do CST proposto, construiu-se um protótipo que adiciona tensão em onda quadrada em fase com o afundamento de tensão proveniente da fonte de entrada. A fig. 17 apresenta a topologia do conversor construído. Dois estágios com a mesma relação de transformação foram utilizados, 1:0,2, fazendo com que na soma dos dois a relação total fosse de 1:0,4. Conforme fig. 10, o compensador é capaz de recuperar afundamentos de tensão de até $0,65 \mathrm{pu}$, visando a recuperação da amplitude da tensão para 0,9 pu. A tabela 2 traz os componentes utilizados no CST multinível. O controle utilizado foi o descrito na fig. 13, sendo o capacitor e resistor do estimador, respectivamente, $4,7 \mu \mathrm{F}$ e $5,6 k \Omega$. Para os comparadores utilizou-se o LM311.

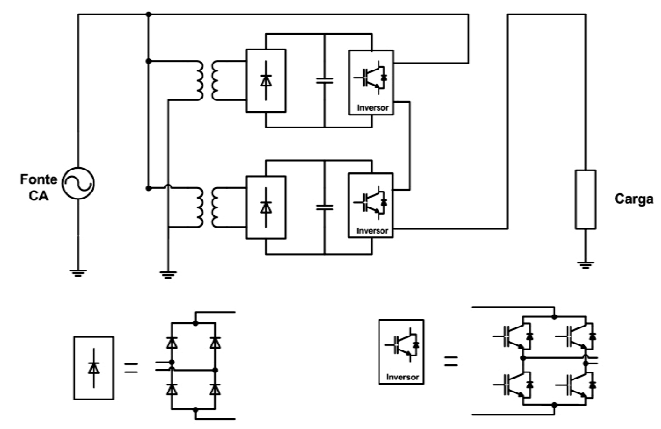

Figura 17: CST Multinível montado para proteção de afundamentos de tensão.

Um microcomputador (PC) foi utilizado como carga a ser protegida pelo compensador. As fig. 18 a 20 mostram os resultados obtidos com CST protegendo o $\mathrm{PC}$. O computador
Tabela 2: Componentes utilizados no CST multinível para proteção de afundamentos de tensão monofásico.

\begin{tabular}{l|l}
\hline Componentes & Especificação \\
\hline Transformador & $120: 24,100 \mathrm{VA}$ \\
\hline Capacitor c.c & $470 \mu F$ \\
\hline Inversosr & LMD18200 \\
\hline Retificador & Canon KBU $8 \mathrm{~K}, 800 \mathrm{~V} / 8 \mathrm{~A}$ \\
\hline Estimador DCR & $R=5,6 k \Omega$ e $C=4,7 \mu F$ \\
\hline Comparadores & LM311 \\
\hline
\end{tabular}

utilizado possui processador Pentium $4,2 \mathrm{GHz}, 512 \mathrm{Mb}$ de RAM, HD de $80 \mathrm{~Gb}$ e fonte de alimentação de 350W.

A fig. 18 mostra o afundamento que implicava no religamento do microcomputador. Nesta figura, visualiza-se o nível de afundamento máximo suportado pelo PC: $72 \%$ (130Vp em $180 \mathrm{Vp}$-nominal) e $16 \mathrm{~ms}$ (1 período na frequência fundamental). No canal 2 , a corrente proveniente da fonte de tensão que alimenta a placa mãe é monitorada. O seu brusco decaimento é devido ao desligamento do processador principal.

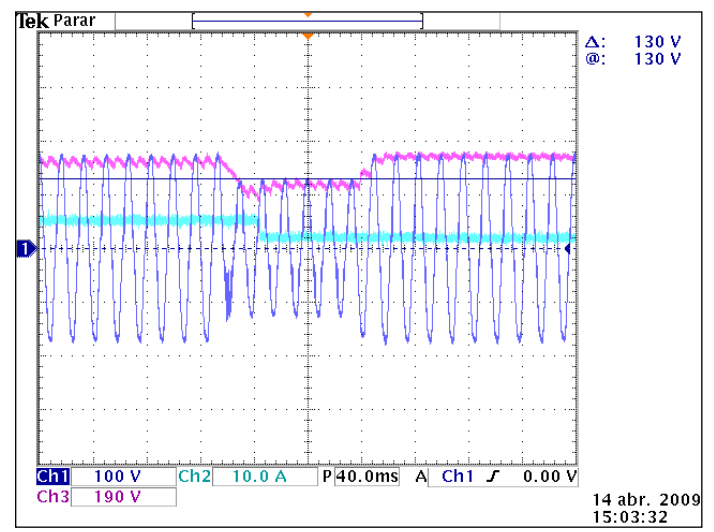

Figura 18: Afundamento de $72 \%$ no microcomputador sem CST em onda quadrada.

As fig. 19 e 20 mostram o afundamento de $72 \%$ aplicado ao protótipo do CST multinível proposto. Na fig. 20, o canal 4 , em verde claro, apresenta a onda resultante entre o afundamento proveniente da fonte de entrada e a onda quadrada injetada pelo compensador série. Observa-se que o computador não religa pois a corrente do processador se manteve constante. Com o CST multinível em operação, a suportabilidade do PC passou para 58\% da tensão nominal. Sem o compensador, $72 \%$ da tensão nominal eram necessários para manter o PC em operação, para afundamentos com duração maior que um período da frequência fundamental. Conforme estudo de (Melhorn et al., 2005), 53\% da incidência de afundamentos acontecem em afundamentos com tensão residual de no mínimo $70 \%$. Para afundamentos com tensões residu- 
ais de no mínimo 55\%, a incidência passa para $75 \%$. Assim, com o CST em onda quadrada protegendo o PC, a suportabilidade passa para $75 \%$ dos afundamentos mais frequentes.

Na fig. 19, após o início do afundamento, o compensador passa a injetar tensão após 0,5 ciclo. Isto se deve ao tempo de resposta do estimador DCR de entrada que, para uma afundamento de $72 \%$ e os componentes escolhidos, seria de 8,6 $\mathrm{ms}$, aproximadamente 0,5 ciclo, conforme eq. 5 . Este afundamento teve a injeção de tensão proveniente da soma das duas células, ou seja, relação de 1:0,4, conforme fig. 10.

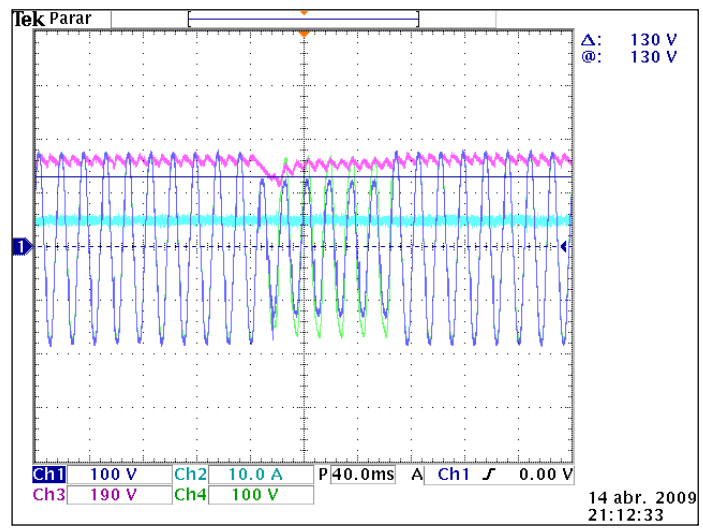

Figura 19: Afundamento de $72 \%$ no microcomputador com CST em onda quadrada.

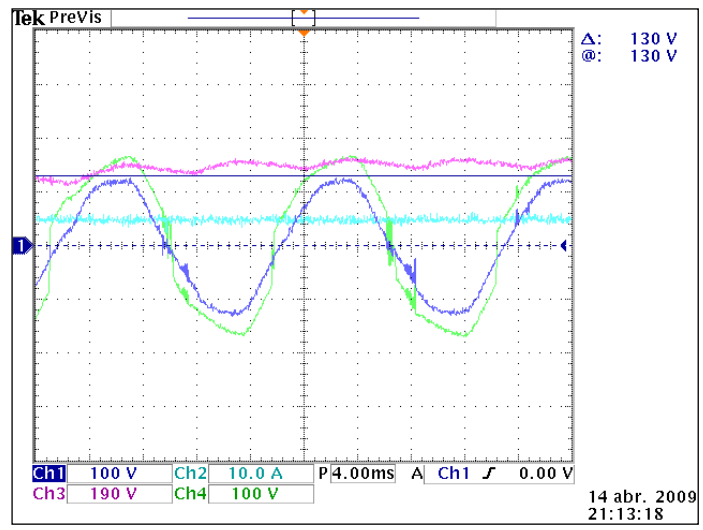

Figura 20: Afundamento de $72 \%$ no microcomputador com CST em onda quadrada - detalhes.

Um CST trifásico, de mesma topologia da fig. 15, foi montado. Replicou-se para as três fases a estrutura da fig. 17, com os mesmos componentes mencionados na tabela 2. Entretanto, o controle implementado foi aquele descrito na seção 4, fig. 16. Para o controle utilizou-se a placa de controle UPCC-2812 da empresa HPE, que utiliza o DSP TMS320F2812 da Texas Instruments. As fig. 21 e 22 apresentam os resultados experimentais coletados. Aplicou-se um afundamento desequilibrado, com os seguintes valores de tensão: $V_{a}=63 \%, V_{b}=63 \%$ e $V_{c}=82 \%$. Além das tensões há um sinal de detecção fornecido pela placa de controle. Ele muda seu estado de baixo para alto durante a injeção do afundamento, conforme pode ser visto na fig. 22 . As fig. 23 e 24 mostram, respectivamente, os valores eficazes das tensões de fase apresentadas nas fig. 21 e 22 . Na fig. 24 foi incluído duas linhas tracejadas representando 0,9 e 1,05 pu. Percebe-se, desta forma, que a recuperação em onda quadrada conseguiu mitigar o afundamento de tensão trifásico, preservando a tensão entre o intervalo de 0,9 e 1,05 pu.

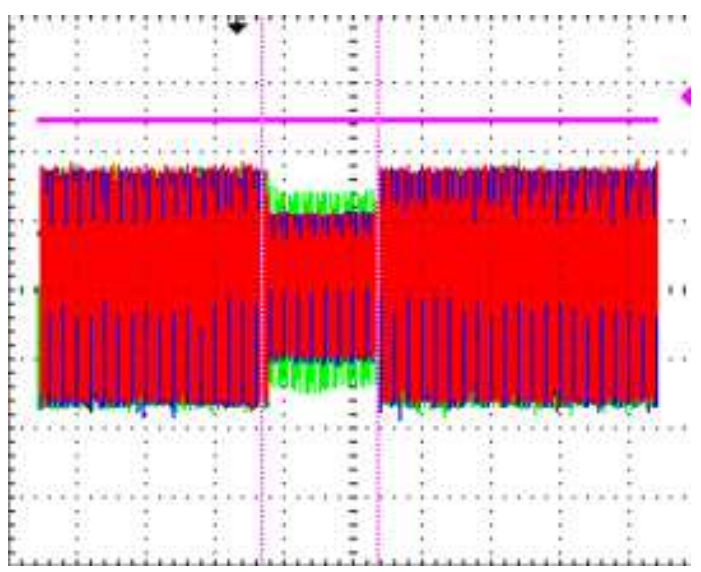

Figura 21: : Afundamento Trifásico. $V_{a}=63 \%, V_{b}=63 \% \mathrm{e}$ $V_{c}=82 \%$.

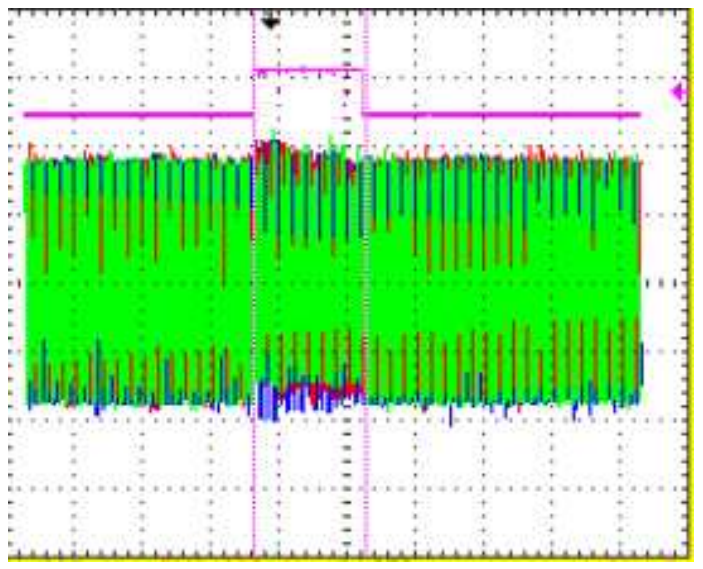

Figura 22: Afundamento Trifásico compensado pelo CST em Onda Quadrada. $V_{a}=63 \%, V_{b}=63 \%$ e $V_{c}=82 \%$.

\section{COMPARATIVO ENTRE CST ONDA QUADRADA E SENOIDAL}

A escolha entre o Compensador Série de Tensão em Onda Quadrada e Senoidal se dá por um comparativo entre as van- 


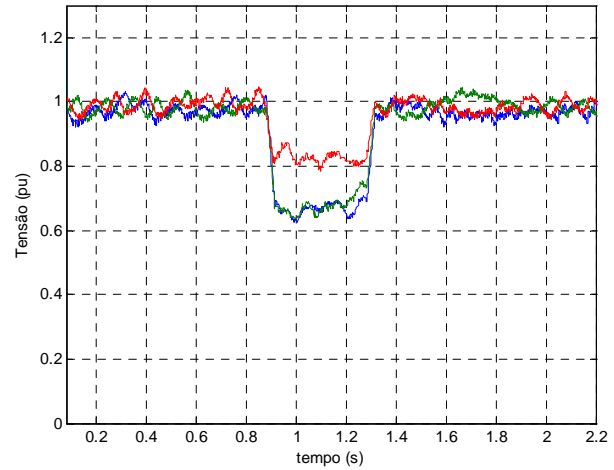

Figura 23: Valores eficazes do Afundamento Trifásico mostrado na fig. 21.

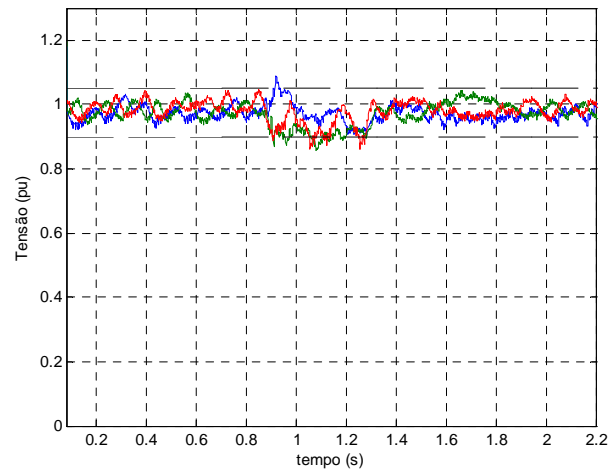

Figura 24: Valores eficazes do Afundamento Trifásico compensado mostrado na fig. 22.

tagens e desvantagens técnicas, e também entre os custos empregados na montagem de cada compensador.

Uma vantagem do CST senoidal em relação ao de onda quadrada é a utilização da modulação PWM por dois motivos: facilidade de modulação da tensão e possibilidade de compensação de outros distúrbios de qualidade de energia elétrica (QEE), tais como filtro de harmônicos de tensão, mitigação de fenômenos como desequilíbrio de tensão, flicker e outros, conforme enunciado na introdução. Entretanto, há uma desvantagem no uso do PWM em sistemas de grande potência: o chaveamento em alta frequência de grandes blocos de potência geram diversos problemas de compatibilidade eletromagnética, necessitando de filtros passivos para mitigar estas ocorrências (Mihalic and Kos, 2006). O filtro LC de saída no conversor série representa em torno de $20 \%$ do volume do equipamento final (Lopes et al., 2006). Sua retirada significa um aumento $25 \%$ na densidade total de potência.
O CST em onda quadrada, na topologia proposta neste trabalho, apresenta um número maior de componentes se comparado com as estruturas clássicas de CSTs senoidais. Este número maior se dá pela necessidade de modulação da tensão série a ser injetada. Apesar de não ser tão flexível acerca da mitigação de problemas de QEE, o CST em onda quadrada consegue mitigar desequilíbrios de tensão, conforme descrito em Pires et al. (2010). A mudança de modulação, de PWM para onda quadrada, faz com que as perdas no conversor série diminuam em 30\% (Lopes et al., 2004).

Para um estudo comparativo em termos de custo, Lopes et al. (2006) foi utilizada como referência (projeto 2, especificado no citado artigo). Neste, é apresentado um custo de um CST senoidal trifásico de 300kVA, 440V. A capacidade de mitigação de afundamentos vai até $50 \%$ de tensão remanescente. Preferiu-se projetar um compensador monofásico de menor potência e tensão, $15 \mathrm{kVA}, 220 \mathrm{~V}$, mas ainda mitigando afundamentos de até $50 \%$. Esta escolha se deu pela maior gama de componentes disponíveis para consulta de preços, realizada em sites especilizados. O percentual que cada parte integrante representa no custo do CST senoidal foi utilizada conforme descrito no projeto 2 de Lopes et al. (2006). Projetou-se também um CST em onda quadrada que atingisse o mesmo requisitos (afundamentos com 50\% de tensão). Conforme discutido na seção 2, apenas duas células são necessárias para cobrir a faixa de afundamentos especificada: 1:0,2 e 1:0,6. Cada parte integrante, assim como seu projeto, é detalhado ao longo desta seção. Os custos de cada projeto são mostrados na tabela 3 , lembrando que a base $1 \mathrm{pu}$ é a mesma nos dois projetos e significa o custo total do CST senoidal.

Os dois projetos, ao invés de trabalharem em hot stand-by, ou seja, injeção de tensão zero na ausência de afundamento, utilizarão uma chave de by-pass, que consiste em dois tiristores em anti-paralelo. Como o projeto desta chave depende da carga, nos dois compensadores são utilizados os mesmos tiristores, tendo, portanto, os mesmos custos. Estes, desta forma, não entrarão no custo final.

\section{Chaves do inversor}

Para o projeto destas chaves é necessário especificar a corrente que por ela circulará, bem como a tensão reversa máxima. A corrente, em qualquer dos dois projetos, será a mesma, sendo esta a corrente de carga, aproximadamente 70A. A tensão reversa máxima no CST senoidal será de 311V. Utilizando IGBTs, a família disponível com estes níveis de corrente e tensão são módulos de 70A e 600V.

No caso das células do conversor em onda quadrada, para a célula com transformador de relação de transformação 1:0,2, a tensão máxima reversa é de $62 \mathrm{~V}$. Com relação 1:0,6, a ten- 
são máxima reversa $187 \mathrm{~V}$. Estes valores fazem com que, ao invés de utilizar IGBTs, podem-se utilizar Mosfets com tensão reversa de $100 \mathrm{~V}$ e $200 \mathrm{~V}$. Esta escolha tem um impacto direto no custo final do equipamento.

Em relação às perdas nas chaves do inversor, os Mosfets utilizados no CST em onda quadrada apresentam tensões de bloqueio de $100 \mathrm{~V}$ e $200 \mathrm{~V}$. Nesta faixa de tensão de bloqueio, as perdas de condução de Mosfets são menores ou equivalentes às perdas de condução de IGBTs. Entretanto, por haver o dobro de número de chaves no CST em onda quadrada, as perdas de condução serão maiores, mas as perdas de chaveamento são desprezíveis. Como exemplo, utilizando Mosfets Fairchild 70A/100V (FQA70N10) e 70A/200V (FDA70N20), os quais possuem perdas de condução iguais a $452 \mathrm{~W}$ e $684 \mathrm{~W}$, respectivamente, conduziando corrente nominal. As perdas totais no CST em onda quadrada, utilizando-se dos referidos Mosfets, é igual a 1136W. Utilizando IGBTs Fairchild HGTG40N60B3 no CST senoidal, em uma frequência de chaveamento de $10 \mathrm{kHz}$, com a mesma corrente nominal, as perdas de condução são iguais a 644W enquanto as perdas de chaveamento são $328 \mathrm{~W}$, totalizando 1012W. Desta forma, as perdas no inversor do CST em onda quadrada é apenas $12,3 \%$ maior em relação às perdas no CST senoidal, apesar do maior número de chaves, devido às baixas perdas de chaveamento. Importante destacar que, tanto no CST em onda quadrada quanto no senoidal, o tempo de utilização destas chaves é curto comparado com o tempo de total de trabalho do compensador protegendo a carga. A maior parte do tempo, o compensador ficará transpassado pelos tiristores de bypass, injetando tensão de recuperação apenas na ocorrência de um afundamento de tensão, o que normalmente dura algumas centenas de milisegundos. Desta afirmação, pode-se também constatar que o uso de dissipadores é dispensável. A explicação para tal advém das constantes de tempo térmicas das bases de módulos de potência serem da ordem de centenas de milisegundos. Assim, quase não há transferência de energia térmica do módulo para o meio durante a operação, tornando, portanto, o dissipador dispensável (Lopes et al., 2006).

Conforme Lopes et al. (2006), o módulo IGBT representa $0,38 \mathrm{pu}$ do custo final do equipamento. Após consulta em sites de venda de componentes eletrônicos, módulos Mosfet com tensão de $100 \mathrm{~V}$ e $200 \mathrm{~V}$ custam $20 \%$ e $30 \%$, respectivamente, em relação ao IGBT de mesma corrente e tensão 600V. Assim, apesar do número de chaves ser o dobro, o custo final das chaves do inversor para o CST em onda quadrade é 50\% do custo da opção baseada em inversor PMW a IGBT, ficando portanto em 0,19 pu.

\section{Gate Driver}

Para o custo do gate driver, utilizou-se uma relação constante entre o preço dos dispositivos de potência e os seus respectivos gate drivers. Esta opção se justifica uma vez que os MOSFETs utilizados na topologia em cascata operam em tensões mais baixas, o que amplia significativamente o número de soluções para a implementação dos gate drivers. Como resultado, o custo total associado aos gate drivers permanece constante e igual a $0,1 \mathrm{pu}$.

\section{Transformador shunt}

No projeto do CST senoidal, o transformador utilizado tem relação de 1:1. A potência que cada módulo irá entregar será proporcional à sua relação de transformação. Logo, 0,2 e 0,6 pu para as duas células do CST em onda quadrada. Em termos de custo, o transformador com 0,2 pu custa $55 \%$ e 0,6 pu $68 \%$ em relação ao transformador $1: 1$. O custo final ficará em $123 \%, 0,16$ pu (0,13 pu para CST senoidal).

\section{Capacitor}

O valor da capacitância do barramento c.c. é dado pela equação (6), conforme demonstrado em (Silva and Filho, 2002).

$$
C \geq \frac{I_{L}}{w \Delta V_{D C}}
$$

Considerando $5 \%$ de ripple no barramento c.c., quanto menor a tensão no capacitor, maior será seu valor. Na célula com relação de transformação 1:0,2, o valor do capacitor será 5 vezes maior que o capacitor do CST senoidal (relação 1:1), enquanto a célula com 1:0,6 será 1,7 vezes maior. Porém, apesar da diferença no valor da capacitância, as tensões nos capacitores serão menores, o que impacta significativamente no preço final deste componente. Agregando estas duas informações, o capacitor da célula 1:0,2 é 53\% e da célula 1:0,6 $78 \%$ do preço de referência do capacitor do CST senoidal. O custo do CST em onda quadrada para seus capacitores será de 0,08 pu (0,06 pu para CST senoidal).

\section{Retificador}

A especificação deste componente se dá pelo corrente direta e tensão reversa máxima, assim como as chaves do inversor. $\mathrm{Na}$ topologia escolhida para o projeto dos dois conversores, a potência a ser injetada é retirada da própria rede. Assim, a corrente que se circulará por estes componentes será a corrente de carga mais a corrente necessária para o carregamento do capacitor. Nos três projetos, a corrente será praticamente a mesma. Assim, o que diferencia será a tensão reversa que cada componente irá suportar. Entretanto, a diferença de 
preço na faixa de tensão considerada $(100 \mathrm{~V}$ a $400 \mathrm{~V})$ para um mesmo valor de corrente é insignificante. Assim, por ter o dobro de chaves retificadoras, o CST em onda quadrada terá um custo duas vezes maior $(0,08 \mathrm{pu})$ em relação ao CST senoidal $(0,04 \mathrm{pu})$.

\section{Filtro Senoidal}

O custo do filtro senoidal existirá apenas no CST senoidal, sendo este valor de $0,07 \mathrm{pu}$.

\section{Barramentos e Miscelânia}

Este item retrata custos de construção e acessórios na construção do protótipo. Por haver pouco detalhes na referência consultada (Lopes et al., 2006), preferiu-se, para fins de comparação final, considerar o custo igual nos dois projetos.

\section{Custo Final}

O custo final nos dois projetos foi de 0,73 pu para o CST em onda quadrada e 1 pu para o CST senoidal. Houve uma diferença de $27 \%$, em favor do CST em onda quadradra, provando ser o CST em onda quadrada com duas células uma alternativa economicamente viável ao CST senoidal.

\section{CONCLUSÕES}

Este artigo apresentou a proposta de um compensador série de tensão em onda quadrada e de seu controle. Este tipo de compensador é adequado, principalmente, para mitigação de afundamentos de tensão em cargas eletrônicas. O CST em onda quadrada visa a manutenção do valor da tensão no filtro capacitivo através da injeção da tensão em onda quadrada. A tensão resultante na carga corresponde então à soma da tensão remanescente da rede c.a. com a tensão em onda quadrada proveniente do CST.

A grande vantagem da injeção da tensão em onda quadrada é a eliminação do filtro senoidal de saída e eliminação da modulação em alta frequência do inversor de saída. A modificação na modulação faz com que o controle do CST em onda quadrada fique bastante simples, podendo inclusive ser implementado por componentes discretos, sem a necessidade de uso de microprocessadores.

Como a tensão em onda quadrada tem amplitude fixa, inicialmente teria-se uma limitação de compensação pois poderiase afirmar que apenas uma estreita faixa de afundamentos poderia ser compensada. Entretanto, normas internacionais recomendam que equipamentos eletrônicos devam funcionar com tensões de alimentação variando entre 0,9 e 1,05 pu (ANSI-C84.1, 2006; IEEE Std 1159, 1995). Este princípio
Tabela 3: Custo comparativo por módulo monofásico.

\begin{tabular}{|c|c|c|c|}
\hline & CST & $\begin{array}{l}\text { Número de } \\
\text { componentes }\end{array}$ & $\begin{array}{l}\text { Custo } \\
\text { final }\end{array}$ \\
\hline \multirow{2}{*}{$\begin{array}{l}\text { Chaves do } \\
\text { inversor }\end{array}$} & Sen. & 4xIGBTs (70A / 600V) & $0,38 \mathrm{pu}$ \\
\hline & $\begin{array}{l}\text { Onda } \\
\text { Quad. }\end{array}$ & $\begin{array}{l}\text { 4xMosfets }(70 \mathrm{~A} / 100 \mathrm{~V})+ \\
4 x M o s f e t s(70 \mathrm{~A} / 200 \mathrm{~V})\end{array}$ & $0,19 \mathrm{pu}$ \\
\hline \multirow{2}{*}{$\begin{array}{l}\text { Gate Driver } \\
\text { (ponte-H) }\end{array}$} & Sen. & 1 & $0,10 \mathrm{pu}$ \\
\hline & $\begin{array}{l}\text { Onda } \\
\text { Quad. }\end{array}$ & 2 & $0,10 \mathrm{pu}$ \\
\hline \multirow[t]{2}{*}{ Transformador } & Sen. & 1 & $0,13 \mathrm{pu}$ \\
\hline & $\begin{array}{l}\text { Onda } \\
\text { Quad. }\end{array}$ & 2 & $0,16 \mathrm{pu}$ \\
\hline \multirow[t]{2}{*}{ Capacitor } & Sen. & 1 & $0,06 \mathrm{pu}$ \\
\hline & $\begin{array}{l}\text { Onda } \\
\text { Quad. }\end{array}$ & 2 & $0,08 \mathrm{pu}$ \\
\hline \multirow[t]{2}{*}{ Retificador } & Sen. & 4 & $0,04 \mathrm{pu}$ \\
\hline & $\begin{array}{l}\text { Onda } \\
\text { Quad. }\end{array}$ & 8 & $0,08 \mathrm{pu}$ \\
\hline \multirow[t]{2}{*}{ Filtro Senoidal } & Sen. & 1 & $0,07 \mathrm{pu}$ \\
\hline & $\begin{array}{l}\text { Onda } \\
\text { Quad. }\end{array}$ & - & - \\
\hline \multirow{2}{*}{$\begin{array}{l}\text { Barramentos e } \\
\text { Miscelânia }\end{array}$} & Sen. & 1 & $0,12 \mathrm{pu}$ \\
\hline & $\begin{array}{l}\text { Onda } \\
\text { Quad. }\end{array}$ & 1 & 0,12 \\
\hline \multirow[t]{2}{*}{ Dissipador } & Sen. & 1 & $0,10 \mathrm{pu}$ \\
\hline & $\begin{array}{l}\text { Onda } \\
\text { Quad. }\end{array}$ & - & - \\
\hline \multirow[t]{2}{*}{ Custo Final } & Sen. & \multicolumn{2}{|l|}{$1 \mathrm{pu}$} \\
\hline & $\begin{array}{l}\text { Onda } \\
\text { Quad. }\end{array}$ & \multicolumn{2}{|l|}{$0,73 \mathrm{pu}$} \\
\hline
\end{tabular}

está contido na Modulação em Amplitude por degraus, realizados, neste trabalho, através da estrutura multinível em cascata. Procedendo desta forma, poucos níveis são necessários para a compensação de uma grande faixa de afundamentos.

Resultados experimentais foram coletados a partir da construção de um protótipo de CST em onda quadrada. Um computador pessoal (PC) tipo desktop foi usado como carga a ser protegida. A suportabilidade do PC com o CST monofásico passou de $72 \%$ para $58 \%$, ou seja, o PC passou a desligar apenas quando a tensão residual de entrada fosse menor que $58 \%$. O controle apresentou um tempo de resposta de $8 \mathrm{~ms}$, o que não comprometeu a proteção do $\mathrm{PC}$, já que esta carga permanece ligada, mesmo sem energia na entrada, por $16 \mathrm{~ms}$. 
Uma estimativa de custo com um CST senoidal e um CST em onda quadrada para compensação de afundamentos de tensão de até $50 \%$ na tensão remanescente, mostrou uma economia de $27 \%$ a favor do CST em onda quadrada. Porém, o CST senoidal consegue cobrir uma gama maior de problemas de QEE se comparado com o CST em onda quadrada. Apesar de um pouco mais caro, escolhe-se o CST senoidal quando for necessário um compensador que mitigue vários fenômenos de distúrbio de tensão. Além da economia em termos de custo, outro argumento a favor do CST em onda quadrada reside no fato de ter um maior número de chaves na saída: ainda que uma célula parasse de funcionar, a capacidade de compensação ficaria comprometida mas não eliminada. Outro fato positivo em relação ao CST em onda quadrada está no fato de que as células possuem a mesma tecnologia, ou seja, componentes de mesma especificação em termos de corrente e principalmente tensão. Para compensar afundamentos muito severos, com tensão residual menor que $50 \%$, basta incluir quantas células forem necessárias. Já para o CST senoidal, é necessário refazer o projeto e incluir componentes de maior nível de tensão, pois o transformador shunt deverá elevar a tensão c.a. Como consequência, as chaves deverão suportar tensões superiores ao valor de máximo da tensão c.a. nominal. Como exemplo, um CST senoidal para recuperar um afundamento para $0,1 \mathrm{pu}$, deverá ter um transformador com ganho 1:9. Na ausência de distúrbio, a tensão no barramento c.c. terá uma amplitude nove vezes maior que a tensão c.c. nominal. Tomando como exemplo uma rede de $220 \mathrm{~V}$, a tensão c.c. atingiria $2800 \mathrm{~V}$ em regime normal. Neste caso, seria necessário utilizar semicondutores de média tensão no CST senoidal, visando a proteção de uma carga de baixa tensão.

\section{AGRADECIMENTOS}

Os autores gostariam de agradecer ao CNPq o suporte financeiro para este projeto.

\section{REFERÊNCIAS}

ANSI-C84.1 (2006). Electric power systems and equipment voltage ratings $(60 \mathrm{hz})$.

Bianchin, C., Demonti, R., Paulillo, G., Ortega, M., Gruppelli Jr., F. and Takiguchi, C. (2008). Pesquisa e aplicação de restauradores dinâmicos de tensão (dvr) em linhas de distribuição, IEEE Conferência Internacional de Aplicações Industriais, 2008, Poços de Caldas. Anais do IEEE Induscon 2008.

Bollen, M. (1999). Understanding Power Quality Problems: Voltage Sags and Interruptions, Wiley - IEEE Press.
Brumsickle, W., Schneider, R., Luckjiff, G., Divan, D. and McGranaghan, M. (2001). Dynamic sag correctors: cost-effective industrial power line conditioning, IEEE Transactions on Industry Applications 37(1): 212-217.

Costa Jr., D., Neto, J. A. M. and Aredes, M. (2004). Análise de uma estratégia de controle para restauradores dinâmicos de tensão, $X V$ Congresso Brasileiro de Automática (CBA 2004).

Hill, W. and Harbourt, C. (1999). Performance of medium voltage multi-level inverters, Industry Applications Conference, 1999. Thirty-Fourth IAS Annual Meeting. Conference Record of the 1999 IEEE, Vol. 2, pp. 1186-1192.

IEEE Std 1159, I. (1995). Ieee recommended practice for monitoring electric power quality, IEEE Std 1159-1995 p. i.

Kolev, L. V. (1993). Interval methods for Circuit Analysis, World Scientific Pub Co Inc.

Loh, P. C., Vilathgamuwa, D., Tang, S. K. and Long, H. (2004). Multilevel dynamic voltage restorer, IEEE Power Electronics Letters 2(4): 125-130.

Lopes, B. M., Silva, S. M. and Cardoso Filho, B. J. (2004). Power loss estimation in static power converters, VI International Conference on Industrial Applications - Induscon. Joinvile, 2004.

Lopes, B. M., Silva, S. M., Cardoso Filho, B. J., Brito, J. and Travassos, G. (2006). Análise crítica de dispositivos estáticos de compensação série de baixa tensão com transformadores shunt: Custos versus funcionalidade, Eletrônica de Potência 11: 53-60.

Marafão, F., Colón, D., Negri, C., Jardini, J., Komatsu, W., Matakas, L., Malassi, M., Ahn, S., Bormio Jr, E., Camargo, J., Monteiro, T. and Oliveira, M. (2008). Analysis and design of a multiloop controller and a voltage reference generator for a dvr implementation, IEEE Conferência Internacional de Aplicações Industriais, 2008, Poços de Caldas. Anais do IEEE Induscon 2008.

McGranaghan, M., Mueller, D. and Samotyj, M. (1993). Voltage sags in industrial systems, IEEE Transactions on Industry Applications 29(2): 397-403.

Melhorn, C.J., S., Maitra, A., Sunderman, W., Waclawiak, M. and Sundaram, A. (2005). Distribution system power quality assessment phase ii: voltage sag and interruption analysis, Petroleum and Chemical Industry Conference, 2005. Industry Applications Society 52nd Annual, pp. 113-120. 
Mihalic, F. and Kos, D. (2006). Reduced conductive emi in switched-mode dc ndash;dc power converters without emi filters: Pwm versus randomized pwm, IEEE Transactions on Power Electronics 21(6): 1783-1794.

Nielsen, J. and Blaabjerg, F. (2005). A detailed comparison of system topologies for dynamic voltage restorers, IEEE Transactions on Industry Applications 41(5): 1272-1280.

Pires, I. and de Jesus Cardoso Filho, B. (2009). Cost effective voltage sag mitigation using square-wave series compensators, IEEE Energy Conversion Congress and Exposition, 2009. ECCE 2009., pp. 578-583.

Pires, I., de Jesus Cardoso Filho, B. and de Oliveira, J. (2010). A series voltage regulator based on quasisinusoidal waveform to achieve smart-grid requirements, IEEE Industry Applications Society Annual Meeting (IAS), 2010, pp. 1-7.

PRODIST (2008). Procedimentos de distribuição de energia elétrica no sistema elétrico nacional, Technical report, ANEEL - Agência Nacional de Energia Elétrica.

Pryde, V. (2008). Application of voltage sag mitigation devices in industry:, IEEE/PES Transmission and Distribution Conference and Exposition, 2008., pp. 1-3.

Silva, S., da Silveira, S., Reis, A. and Filho, B. (2005). Analysis of a dynamic voltage compensator with reduced switch-count and absence of energy storage system, IEEE Transactions on Industry Applications 41(5): 1255-1262.

Silva, S. and Filho, B. (2002). Component-minimized voltage sag compensators, 37th IAS Annual Meeting. Conference Record of the Industry Applications Conference, 2002., Vol. 2, pp. 883-889.

Soeiro, T. B., Petry, C. A. and Perin, A. J. (2009). Estabilizadores de tensão alternada do tipo compensadores de tensão, Eletrônica de Potência 14(2): 97-105.

Woodley, N., Morgan, L. and Sundaram, A. (1999). Experience with an inverter-based dynamic voltage restorer, IEEE Transactions on Power Delivery 14(3): 11811186. 